\title{
A Study of Exertional Headache's Prevalence and Characteristics Among Conscripts
}

\author{
Shahnaz Tofangchiha, ${ }^{1}$ Behnam Rabiee, ${ }^{1}$ and Farzad Mehrabi ${ }^{2, *}$ \\ ${ }^{1}$ Department of Internal Medicine, AJA University of Medical Sciences, Tehran, IR Iran \\ ${ }^{2}$ Department of Neurology, AJA University of Medical Sciences, Tehran, IR Iran \\ "Corresponding author: Farzad Mehrabi, Department of Internal Medicine, School of Medicine, AJA University of Medical Sciences, Tehran, IR Iran. E-mail: \\ FarzadMehrabi48@gmail.com
}

Received 2015 July 12; Revised 2015 November 28; Accepted 2016 January 05.

\begin{abstract}
Background: Headache is one of the most common complaints in today's society. Patterns and prevalence of headache, especially headaches associated with physical activity (Exertional Headache) in the population of conscripts in our country is unknown.

Objectives: In this cross sectional study we tried to answer these questions to some extent.

Patients and Methods: Using a Persian questionnaire based on international headache society criteria of headache types (ICHD-II) and a sample size of 300 , filled by two trained medical doctors, we gathered our data and analyzed it with an acceptable P value of $<0.05$ and a confidence interval of $95 \%$.

Results: Headache prevalence among our conscript participants was 78.7\%. The prevalence of exertional headache was $12.7 \%$. EH sufferers' mean age was 22.16 (SD: 2.60) years. EH was found more often bilaterally and almost equally pulsating or compressive. The main location of pain was frontotemporal region. The most common aggravating and alleviating factors of EH were hot environment and discontinuation of exercise respectively.

Conclusions: Our team provided a reasonable database of exertional headache and its characteristics in conscripts' population which could be used in further investigations to improve their general health and function.
\end{abstract}

Keywords: Epidemiology, Exertional Headache, Conscripts

\section{Background}

Headache is the most common complaint in human societies (1). The exertional headache (EH) has been known for decades but since its characteristics are not precisely known, there is still no specific definition for it. In some studies, they call the headache developed during or after a continuous exercise activity "the exertional headache" and categorize the one caused by Valsalva maneuver into the benign headache after cough (1-5). These types of headaches can be so intense so that they would cause discontinuation of the physical activity and exercise.

Military conscripts do a remarkable amount of daily activity during their military service. Considering the fact that $\mathrm{EH}$ is more common among the youth (6), they are prone to it and its consequences. Hence, determining the prevalence and characteristics of $\mathrm{EH}$ would help to recognize it better and ultimately to prevent it.

\section{Objectives}

This study was performed to identify EH prevalence, pattern, stimulator factors, the way sufferers deal with it, and its aggravating and alleviating factors among military conscripts in Tehran, Iran.

\section{Patients and Methods}

Iranian military conscripts were the target population of this study. Considering the sample size of other studies in this field, and due to the random distribution of conscripts, 300 conscripts were selected randomly from all conscripts entering Afsariyeh 01 training camp, Tehran at 2014.

We used a Persian questionnaire based on the criteria of the International Headache Society (ICDH-II) which was used in a large epidemiologic study of headache in Tehran before with promising results (6).

Based on International Headache Society, primary EH is a pulsating headache, lasting from 5 minutes to 48 hours, caused by exertion, occurs only during or after exertion, 
and is not attributed to another disorder (7). Conscripts who experienced headaches caused by activity were asked to fill out the questionnaire regarding the details of $\mathrm{EH}$, including the site of pain, laterality, quality of pain (throbbing or pressure), duration of pain, frequency of $\mathrm{EH}$, aggravating and alleviating factors for pain, and other symptoms. The pain was measured using a visual analog scale (VAS).

Two trained doctors familiar with the exertional headache, filled out the questionnaires during a face to face interview with each subject. We ruled out headaches caused by sinusitis, colds, or dental problems.

We analyzed our data using IBM SPSS v22, with an acceptable P Value of $<0.05$ and a confidence interval of $95 \%$.

Each questionnaire had a code and names or addresses of the subjects were never mentioned in the process. The methods of this study was confirmed in AJA university of medical sciences ethics committee and informed consent was taken from each participant. We also provided a free medical consultation for those who suffered from headache.

\section{Results}

We analyzed 300 questionnaires filled by 18 - 26 year old male conscripts $($ Mean $=22.34$ years, $S D=2.58$ ).

Out of 300 conscripts, 64 (21.3\%, CI 95\%: 16.8\% - 26.0\%) hadn't experienced any type headache not related to sinusitis, cold or dental problems (headache-free). Therefore prevalence of headache in conscripts of our study was $78.7 \%$ (CI 95\%: 74.0\% - 83.2\%).

Finally, 38 cases $(12.7 \%$, CI 95\%: 9.0\% - 16.5\%) with the mean age of 22.16 years $(\mathrm{SD}=2.60$ ) had suffered exertional headache (EH). Tables 1 and 2 show EH characteristics and its aggravating and alleviating factors.

Out of $38 \mathrm{EH}$ sufferers, 18 (47.4\%, CI 95\%: $28.9 \%$ - $63.2 \%$ ) reported a regular exercise plan in the week and 21 (55.3\%, CI 95\%: 39.5\% - 72.3\%) declared their $\mathrm{EH}$ will occur less frequent if they exercise regularly. Table 3 shows activities which caused EH in our subjects.

Out of 38 EH sufferers, 16 (42.1\%, CI 95\%: 26.3\% - 57.9\%) experienced EH during exercise, 11 (28.9\%, CI 95\%: 14.6\% - 42.1\%) after exercise and 11 cases (28.9\%, CI 95\%: 14.6\% - 42.1\%) experienced it in both situations (during and after exercise).

We used a 10-score visual analog scale (VAS) to reveal the severity of exertional headache (Figure 1).

\section{Discussion}

In this cross-sectional study, we tried to reveal $\mathrm{EH}$ prevalence and characteristics among conscripts.

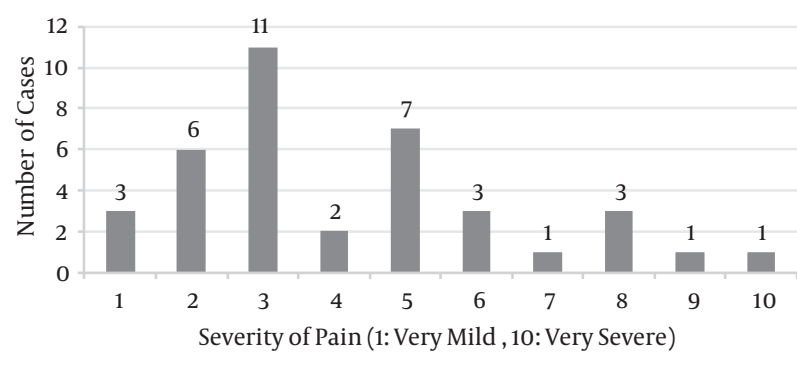

Figure 1. Severity of Pain in an EH Episode

The prevalence of all types of headache in conscripts was $78.7 \%$ (CI 95\%: 74.0\% - 83.2\%). Lifetime prevalence of headache among general population in similar studies was $96.0 \%$ in Denmark (8), 69.1\% in Italy (9), 67.0\% in Hungary (10), $77.2 \%$ in Norway (11), 68.0\% in South Korea $(12,13)$, 83.6\% in Oman (14), 72.5\% in Qatar (14) and 77.0\% in Europe (9). Differences between distribution and mean of general population's age in those countries may affect their results.

Totally 38 (12.7\%) of our subjects had experienced EH. This is slightly higher for the similar age range compared with a recent large epidemiologic study in Tehran which found prevalence of $\mathrm{EH} 7.5 \%$ and $9.1 \%$ in age groups of 12 - 19 and 20 - 39 years respectively (6). This could be due to higher activity rate of military conscripts comparing to general population. However, when comparing these results, it is worth considering that the present study was only performed on male subjects. These results are also in agreement with Sjaastad et al. who found a prevalence of $12.3 \%$ in their large sample sized study (3). Although Chen et al. found EH prevalence $30.4 \%$ in their study (4), it could not be compared to our results since their sample size age range was 13-15 years.

Among EH sufferers $73.7 \%$ reported their headache as bilateral. This finding is similar to results of other studies in this field $(1-3,6,15)$.

Based on our results, the most common location of pain in EH was frontal region (34.2\%) followed by temporal region (16.8\%). Compressive quality was observed in about half of the EH cases and the other half reported pulsatile quality of EH. These results are similar to a recent epidemiologic EH study in Tehran general population (6).

Based on our results, 55.3\% of cases EH started in the first 30 minutes of exercise and more than a third of cases discontinued their exercise due to headache. Thus, control of EH can affect these cases' weekly exercise time and population's health. We could also suggest short breaks during exercise to alleviate the pain before it gets severe.

The most common aggravating factor was exercise in hot weather (81.6\%). This finding reveals the importance of 
Table 1. Exertional Headache Characteristics in Conscripts

\begin{tabular}{|c|c|c|}
\hline Characteristic & No. $(\%)$ & CI 95\% \\
\hline \multicolumn{3}{|l|}{ Laterality } \\
\hline Unilateral & $2(5.3)$ & $0.0 \%-15.8 \%$ \\
\hline Bilateral & $28(73.7)$ & $60.5 \%-86.8 \%$ \\
\hline First unilateral and then bilateral & $8(21.1)$ & $7.9 \%-43.2 \%$ \\
\hline \multicolumn{3}{|l|}{ Location } \\
\hline Frontal & $13(34.2)$ & $18.4 \%-50 \%$ \\
\hline Temporal & $6(16.8)$ & $5.3 \%-28.9 \%$ \\
\hline Holocephalic & $5(13.2)$ & $2.6 \%-26.3 \%$ \\
\hline Occipital & $4(10.5)$ & $2.6 \%-21.1 \%$ \\
\hline Vertex & $3(7.9)$ & $0.0 \%-15.8 \%$ \\
\hline Can't localize & $7(18.4)$ & $6.7 \%-31.6 \%$ \\
\hline \multicolumn{3}{|l|}{ Quality } \\
\hline Pulsating & $18(47.4)$ & $30.4 \%-63.2 \%$ \\
\hline Compressive & $17(44.7)$ & $26.3 \%-60.5 \%$ \\
\hline Can't Determine & $3(7.9)$ & $0.0 \%-18.4 \%$ \\
\hline \multicolumn{3}{|l|}{ Duration } \\
\hline Less than 5 min & $5(13.2)$ & $2.6 \%-23.7 \%$ \\
\hline $5 \mathrm{~min}$ to $1 \mathrm{~h}$ & $15(39.5)$ & $26.3 \%-55.3 \%$ \\
\hline $1 \mathrm{~h}$ to $24 \mathrm{~h}$ & $16(42.1)$ & $26.3 \%-55.3 \%$ \\
\hline More than $24 \mathrm{~h}$ & $2(5.3)$ & $0.0 \%-13.2 \%$ \\
\hline \multicolumn{3}{|l|}{ Frequency (in 10 times of exercise) } \\
\hline$<2$ & $17(44.7)$ & $26.3 \%-60.5 \%$ \\
\hline 2 to 5 & $14(36.8)$ & $21.1 \%-52.6 \%$ \\
\hline$>5$ & $7(18.4)$ & $7.9 \%-31.6 \%$ \\
\hline \multicolumn{3}{|c|}{ Time of getting EH from the onset of exercise } \\
\hline$<30 \mathrm{~min}$ & $21(55.3)$ & $38.3 \%-73.7 \%$ \\
\hline $30 \mathrm{~min}$ to $1 \mathrm{~h}$ & $10(26.3)$ & $13.2 \%-40.7 \%$ \\
\hline $1 \mathrm{hr}$. to $2 \mathrm{~h}$ & $3(7.9)$ & $0.0 \%-18.4 \%$ \\
\hline$>2 \mathrm{~h}$ & $4(10.5)$ & $0.0 \%-21.1 \%$ \\
\hline \multicolumn{3}{|l|}{ Severity } \\
\hline Discontinuation of exercise & $14(36.8)$ & $21.1 \%-53.8 \%$ \\
\hline Total & $38(100)$ & \\
\hline
\end{tabular}

air conditioning and temperature control.

Table 4 summarizes a comparison between this study and 3 other major studies in EH field.

Only 6 out of $38 \mathrm{EH}$ sufferers had visited a doctor for their condition and 3 of them were recommended to stop their exercise. This could be improved by increasing general awareness about serious risks of self-medications and benefits of professional care and treatments.
Hence there are few similar studies done in Iran and the sample sizes of studies in middle east are small, these findings can be useful for completion of database on $\mathrm{EH}$ and its characteristics in conscripts and designing further studies leading to prevention and better management of EH.

Cross-sectional descriptive studies have their limitations such as selection bias, information bias and recall 
Table 2. Aggravating and Alleviating Factors of Exertional Headache in Conscripts

\begin{tabular}{|c|c|c|}
\hline Factors & No. (\%) & CI 95\% \\
\hline \multicolumn{3}{|l|}{ Aggravating factors } \\
\hline Exercise in hot weather & $31(81.6)$ & $68.4 \%-94.7 \%$ \\
\hline Exercise in high altitude & $3(7.9)$ & $0.0 \%-15.8 \%$ \\
\hline Light & $2(5.3)$ & $0.0 \%-15.8 \%$ \\
\hline Sound & $1(2.6)$ & $0.0 \%-7.9 \%$ \\
\hline Coughing & $1(2.6)$ & $0.0 \%-7.9 \%$ \\
\hline \multicolumn{3}{|l|}{ Alleviating factors } \\
\hline Exercise discontinuation & $13(34.2)$ & $21.1 \%-51.2 \%$ \\
\hline Sleeping & $10(26.3)$ & $10.5 \%-42.1 \%$ \\
\hline Sweat or food consumption & $9(23.7)$ & $10.5 \%-36.8 \%$ \\
\hline Pain killer & $5(13.2)$ & $2.6 \%-26.3 \%$ \\
\hline Liquid consumption & $1(2.6)$ & $0.0 \%-7.9 \%$ \\
\hline Total & $38(100)$ & \\
\hline Activity & No. (\%) & CI 95\% \\
\hline Aerobic exercise & $11(28.9)$ & $15.8 \%-44.7 \%$ \\
\hline Body building and lifting & $8(21.1)$ & $7.9 \%-34.2 \%$ \\
\hline Football and volleyball & $7(18.4)$ & $7.9 \%-31.6 \%$ \\
\hline Walking & $6(15.8)$ & $5.3 \%-26.3 \%$ \\
\hline Stairs or slippery slope & $4(10.5)$ & $2.6 \%-21.1 \%$ \\
\hline Routine home work & $2(5.3)$ & $0.0 \%-15.8 \%$ \\
\hline Total & $38(100)$ & \\
\hline
\end{tabular}

bias. Recall bias may lead to report a lower prevalence of EH in our study. We tried to lower this bias by a face to face interview and expending plenty of time discovering the pain's nature. On the other hand, Cross-sectional descriptive studies are less expensive than cohorts. Designing a cross-sectional descriptive study as the first step for investigations on $\mathrm{EH}$ seems reasonable considering limited studies done in this field.

\section{Acknowledgments}

Authors would like to thank Dr Payam Mohammadinejad and Dr Bamdad Sadeghi who helped gathering data for this study.

\section{Footnote}

Funding/Support: This study was financially supported by AJA University of medical sciences. 
Table 4. A Comparison of Most Common Characteristics of EH Between Studies

\begin{tabular}{|c|c|c|c|c|c|c|c|c|}
\hline Studies & Sample Size & Age Range, $Y$ & $\begin{array}{l}\text { Gender Pre- } \\
\text { ponderance }\end{array}$ & Prevalence,\% & Quality & Duration & Location & $\begin{array}{l}\text { Aggravating } \\
\text { Factors }\end{array}$ \\
\hline Present study & 300 & $18-26$ & Male only & 12.70 & $\begin{array}{l}\text { Both pulsating } \\
\text { and } \\
\text { compressive }\end{array}$ & $\begin{array}{l}\text { Mostly } 5 \mathrm{~min} \\
\text { to } 24 \mathrm{~h}\end{array}$ & $\begin{array}{l}\text { Bilateral } \\
\text { (73.7\%), more } \\
\text { frequent in } \\
\text { Frontotempo- } \\
\quad \text { ral } \\
\text { region }\end{array}$ & $\begin{array}{l}\text { Exercise in hot } \\
\text { weather }\end{array}$ \\
\hline $\begin{array}{l}\text { Rabiee et al. } \\
\text { (6) }\end{array}$ & 2076 & $12-69$ & Male $>$ Female & 7.30 & $\begin{array}{l}\text { Both pulsating } \\
\text { and } \\
\text { compressive }\end{array}$ & $\begin{array}{c}\text { Mostly } 5 \mathrm{~min} \\
\text { to } 24 \mathrm{~h}\end{array}$ & $\begin{array}{l}\text { Bilateral } \\
(68.4 \%), \text { more } \\
\text { frequent in } \\
\text { Frontotempo- } \\
\text { ral } \\
\text { region }\end{array}$ & $\begin{array}{c}\text { Exercise in hot } \\
\text { weather and } \\
\text { high altitude }\end{array}$ \\
\hline Chen et al. (4) & 1963 & $13-15$ & Female $>$ Male & 30.40 & $\begin{array}{l}\text { Pulsating } \\
(59.4 \%)\end{array}$ & $\begin{array}{l}\text { Short-lasting (1 } \\
\mathrm{h} \text { in } 79 \%)\end{array}$ & $\begin{array}{c}\text { Bilateral } \\
(51.4 \%), \\
\text { involving } \\
\text { frontal region }\end{array}$ & $\begin{array}{l}\text { Short-lasting } \\
\text { Valsalva-like } \\
\text { maneuvers }\end{array}$ \\
\hline $\begin{array}{l}\text { Vaga Study } \\
(1-3)\end{array}$ & 1838 & $18-65$ & Female $>$ Male & 12.30 & Pulsating & $\begin{array}{c}\text { Few min to } 24 \\
\mathrm{~h}\end{array}$ & $\begin{array}{l}\text { Bilateral, } \\
\text { global } \\
\text { involvement } \\
\text { with the pain } \\
\text { maximum in } \\
\text { anterior } \\
\text { region }\end{array}$ & $\begin{array}{l}\text { Effort and } \\
\text { exhaustion } \\
\text { caused by } \\
\text { swimming and } \\
\text { fast walking }\end{array}$ \\
\hline
\end{tabular}

\section{References}

1. Sjaastad O, Bakketeig LS. Exertional headache. I. Vaga study of headache epidemiology. Cephalalgia. 2002;22(10):784-90. [PubMed: 12485203].

2. Sjaastad O, Bakketeig LS. Exertional headache-II. Clinical features Vaga study of headache epidemiology. Cephalalgia. 2003;23(8):803-7. [PubMed: 14510926].

3. Sjaastad O, Bakketeig LS. Prolonged benign exertional headache. The Vaga Study of headache epidemiology. Headache. 2003;43(6):611-5. [PubMed: 12786919].

4. Chen SP, Fuh JL, Lu SR, Wang SJ. Exertional headache-a survey of 1963 adolescents. Cephalalgia. 2009;29(4):401-7. doi: 10.1111/j.14682982.2008.01744.x. [PubMed: 19025550].

5. Pascual J, Iglesias F, Oterino A, Vazquez-Barquero A, Berciano J. Cough, exertional, and sexual headaches: an analysis of 72 benign and symptomatic cases. Neurology. 1996;46(6):1520-4. [PubMed: 8649540].

6. Rabiee B, Mohammadinejad P, Kordi R, Yunesian M. The Epidemiology of Exertional Headache in the General Population of Tehran, Iran. Headache. 2015;55(9):1225-32. doi: 10.1111/head.12610. [PubMed: 26198401].

7. Headache Classification Subcommittee of the International Headache Society. The international classification of headache disorders: 2nd edition. Cephalalgia: An Int J Headache. 2004;24:9-160.
8. Rasmussen BK, Jensen R, Schroll M, Olesen J. Epidemiology of headache in a general population-a prevalence study.JClin Epidemiol. 1991;44(11):1147-57. [PubMed: 1941010].

9. Stovner LJ, Andree C. Prevalence of headache in Europe: a review for the Eurolight project. J Headache Pain. 2010;11(4):289-99. doi: 10.1007/s10194-010-0217-0. [PubMed: 20473702].

10. Bank J, Marton S. Hungarian migraine epidemiology. Headache. 2000;40(2):164-9. [PubMed: 10759917].

11. Russell MB, Kristiansen HA, Saltyte-Benth J, Kvaerner KJ. A crosssectional population-based survey of migraine and headache in 21,177 Norwegians: the Akershus sleep apnea project. J Headache Pain. 2008;9(6):339-47. doi: 10.1007/s10194-008-0077-z. [PubMed: 18850259].

12. Kim BK, Chu MK, Lee TG, Kim JM, Chung CS, Lee KS. Prevalence and impact of migraine and tension-type headache in Korea.J Clin Neurol. 2012;8(3):204-11. doi: 10.3988/jcn.2012.8.3.204. [PubMed: 23091530].

13. Roh JK, Kim JS, Ahn YO. Epidemiologic and clinical characteristics of migraine and tension-type headache in Korea. Headache. 1998;38(5):356-65. [PubMed: 9630788].

14. Benamer HT, Deleu D, Grosset D. Epidemiology of headache in Arab countries.J Headache Pain. 2010;11(1):1-3. doi:10.1007/s10194-009-01738. [PubMed: 19949829].

15. Pearce JM. Cervicogenic headache: a personal view. Cephalalgia. 1995;15(6):463-9. [PubMed: 8706108]. 